\title{
TAALGEBRUIKSNORMERING IN DIE SUID-AFRIKAANSE BANTOETALE
}

\author{
A. Wilkes
}

Taalgebruiksnormering in die Suid-Afrikaanse Bantoetale behels hooksaaklik twee aangeleenthede, namlik die normering van die skryfstelsel, ofte wel die standaardisering daarvan soos dit algemeen onder Bantoetaalkundiges in hierdie land bekend staan, en die skep van nuwe terme. Eersgenoemde staan bekend as die spelreëls en laasgenoemde as die Terminologie. Die redes waarom hierdie twee sake so ' $n$ hoë prioriteit in ons Bantoetale geniet kan die beste verduidelik word met verwysing na twee tydperke in die skryfgeskiedenis van hierdle tale, naamlik die tydperk voor standaardisasie en die tydperk daarna. In die bespreking hiervan in die volgende paragrawe word die aandag hoofsaaklik by die skryfstelsels van die Nguni- en Sothotale bepaa 1 .

Die skryftradisie van die meeste Bantoeskryftale in die RSA kan teruggevoer word na die een of ander jaar in die vorige eeu toe hierde tale vir die eerste mal deur sendelinge op skrif gestel is, Die tale warvan die skryfstelsels toe die lig gesien het was xhosa, zulu, Suid-5otho, Tswana, NoordSotho, Venda en Tsonga.

Van die eerste probleme warmee skrywers van hierdie tale te doen gekry het was hoe om die spraakklanke in hierdie tale wat nie ook in die Europese tale voorkom nie, ortografies voor te stel, en tweedens on te besluit waar die woordgrense in hierdie tale lê aangesien đit toe reeds duidelik was dat die woordverdeling in die Europese tale nie sondermeer op die santoetale oorgeplaas kon word nie. ' $n$ verdere probleem was die talryke dialektiese 
http://spilplus.journals.ac.za/

variasies wat in die klankstelsel van sommige van hierdie tale voorgekom het.

Wat die skryftekenstelsel betref was die situasie in veral die sothotale en in besonder Tswana en Noord-Sotho, uiters benard en het die aanwesigheid van 'n groot aantal dialekte in hierdie tale sake nog meer gekompiseer. In Tswana byvoorbeeld was daar drie onafhanklike ortografieë in gebruik, naamlik die sogenaamde Bloeefonteinse ortografie wat op die Thapingdialek gebaseer was en warin die eerste Bybelgedeelte in Tswana, naanlik die Nuwe Testament, al sover terug as 1840 gepubliseer was, en die Sentrale ortografie wat op die Rolongdialek gebaseer was, en waarin ' $n$ tweede Nuwe Testament in 1894 gepubliseer was. Die derde ortografie wat in Tswana in gebruik was, was die sogenamde mafekingortografie wat vermoedelik op rgatla of Kwena gebaseer was.

In Noord-Sotho was die posisie nog meer verwarrend deurdat, taalkundig gesproke, daar géén taal soos Noord-Sotho bestaan nie. Die skryftaal wat onder hierdie nam bekend staan en wat veronderstel is om op die Pedidialek van Sentraal-Sotho gebaseer te wees, word gebruik deur twee dialekgroepe van Noord-Sotho, naamlik Sentraal-en Noord-Sotho (linguisties gedoel) en ook deur sprekers van twee Periferale Sothodialekgroepe, naamik Noord-oosSotho en Oos-Sotho. Die gevolg hiervan is dat wat vandag nog "Noord-Sotho" genoem word, 'n hoog verwarrende beeld bied. Die opslag van hierdie toestand was dat toe die Sotho-sprekendes van Oos-, Noord- en Noordoos-Transvaal self begin skrywe het, elkeen sy eie dialek gebruik het. Daarmee was alle sprake van ' $n$ standaardaal daarmee heen. ' $n$ Ernstige gevolg van hierdie toestand was dat dit tot 'n verskeidenheid van spelwyses van NoordSotho aanleiding gegee het, wat soveel verwarring veroorsaak het dat die bekende prof. Lestrade na die destydse Noord-Sotho skryfstelsel verwys het as een wat berus het "upon the taste and fancy of the spellers, the result being an olla podrida that can be more easily imagined than described".' so byvoorbeeld was daar net elf konsonante wat deurgaans eenvormig geskrywe was. Hierteenoor was daar egter vyf konsonante wat op drie verskillende wyses geskrywe was, twee op vyf verskillende wyses, drie op ses verskillende wyses, terwyl twee konsonante op sewe en twee op nie minder nie as agt verskillende wyses ortografies gesimboliseer was. 
Asof hierdie "olla podrida" van spellings nie al genoeg was nie, moes daar ook nog rekening gehou word met die gebruik van talryke diakritiese tekens met behulp warvan klanke van pekaar onderskei was. So byvoorbeeld is gebruikgemak van die gewone kappie, ongekeerde kapple, tilde, afkappingsteken, aanhalingstekens, punt, 'onderstreplng ensovoorts wat almal die een of ander ortografiese funksie vervul het.

In vergelyking met die sothotale het sake betreklik rustig verloop in die ortografiese stelsels van die twee Ngunitale, namlik zulu en xhosa. zulu is ' $n$ feitlik homogene taal met weinige indien enige dialekte sodat variasies in die skryftekenstelsel van hlerdie taal minimaal was. Xhosa wat in veel meer heterogene taal as zulu is, het om die een of ander rede nie naastenby die hoeveelheid skryfprobleme ondervind as wat in die sothotale ondervind was nie. Die gevolg niervan was dat die ortografiese sisteme van hierdie twee Ngunttale feitlik van die begin af bale na anmekar was. Die gebruik om aspirasie met behulp van 'n diakritiese teken aan te dui was warskynlik die lastigste skryftekenprobleem warmee xhosa op daardie stadium te doen gehad het.

Wat woordverdeling betref, was die posisie voor 1928 in feitlik al hierdie tale ewe verwarrend en onseker. Die feit dat daar geen formele aanduiding bestaan het van wat alles as woorde in hierdie tale beskou moet word nie, het daartoe gelei dat elke skrywer woorde volgens sy eie goeddunke verdeel het. Mettertyd het twee duidelike neigings onder skrywers van hierdie tale begin posvat, naamlik in neiging om disjunktief te skryf, dit wil sê in terme van klein losstaande linguistlese eenhede, ' $n$ metode wat veral in die Sothotale gevolg was, en ' $n$ teenoorgestelde nelglng, naamik om hierdie eenhede vas te skryf, dit wil sê konjunktief, wat tot langer "woorde" thet komplekse morfologiese strukture anlelding gegee het en wat die metode was wat veral in die Ngunitale gevolg was. Hierbenewens was daar ook nog talle skrywers wat hierdie twee metodes gemeng het, dit wil sê wat of semikonjunktief of semidisjunktief geskrywe het.

Oie gebrek aan orde in die skryfsisteme van die Bantoetale het nie alleen baie skryfprobleme op veral swartskole veroorsak nie, mar het ook dle ontwikkeling van hierdie tale as literête media ernstig in die wiele gery. 
http://spilplus.journals.ac.za/

Die besluit van die owerheid in 1928 om hierdie skryftale te standardiseer was dus allerweë verwelkom.

In 1928 besluit die destydse Unieregering om Die Advieskomitee oor Bantoestudies en -navorsing in die lewe te roep met die opdrag om die skryfstelsels van die verskillende Bantoeskryftale in die land te standadiseer. Uit hierdie komitee word spoedig die Sentrale Ortografiekomitee saamestel wat op $5 y$ beurt weer in vier subkomitees verdeel, naamik die subkomitees vir Sotho, Nguni, Venda en Tsonga. Hierdie subkomitees sou hulle hoofsaaklik met twee sake bemoei, naamlik die standaardisering van die skryftekenstelsels en die opstel van riglyne met betrekking tot die probleem van woordverdeling. Die Sotho- en Ngunikomitees het die byxomstige opdrag ontvang om die ortografieë van hul betrokke tale te probeer verenig.

Die uiteindelike doelstelling van hierdie taalkomitees was om vir elke taal of taalgroep 'n praktiese ortografie daar te stel. In hierdie verband laat hulle hulle sterk lei deur die voorskrifte vervat in 'n memorandum getiteld "Practical orthography of African Languages" wat sterk op die lees van die IPA-beginsels geskoei is en wat deur die International Institute of African Languages and Cultures uitgegee was. Hierin word aanbeveel dat die ortografieë van alle Afrikatale op die Romeinse alfabet gebaseer moet word, dat die tekort aan letters in nierdie alfabet deur spesiale letters aangevul word (soos byvoorbeeld deur die IPA-simbole gebruik te makk) en dat slegs die normuariante van foneme ortografies weerspieël word.

Teen hlerdie agtergrond besluit die onderskeie komitees om, as eerste stap. die bestaande ortografieë as uitgangspunt te neem en dan die leemtes daarin deur sekere wysiginge te probeer uitskakel.

Een van die ingrypendste veranderings wat aanbeveel word is die drastiese inkorting van die gebruik van diakritiese tekens as klankonderskeidende tniddele in die ortografie. Ondervinding het geleer dat op pedagogiese, psigologiese en tipografiese gronde spesial ontwerpte letters verkiesliker is as Romeinse letters met diakritiese tekens: 
"Long experience with systers containing accented letters has shown that in practice the native African very frequently omits the accents and confusion arises in consequence"."

Hierdie besluit lei dartoe dat die gebruik van diakitiese tekens in die ortografiese sisteme van zulu en xhosa feitlik verdwyn. In zulu sou nog slegs ejeksie en in xhosa nog slegs velarisasie (in bepaalde gevalle) deur middel van ' $n$ diakritiese teken' aangedul word. Verder sou ' $n$ spesiaal ontwerpte teken $v$ ir die implosiewe b gebruik word om dit van sy gedeeltelik stemhebbende eksplosiewe teenhanger te onderskei, terwyl khosa ook nog die IPA-simbool $\int$ gebruik het om die medial-palatale frikatief sh voor te stel. Albei hierdie simbole is in latere jare deur gewone ortografiese tekens vervang.

Die vermindering van diakritiese tekens het sonder twyfel die grootste effek op die skryfstelsels van Noord-Sotho en Tswana gehad war soos vroeër genoem, daar van feitlik alle denkbare diakritiese tekens gebruikgemak was. Al wat van hierdie magdom tekens behou gebly het was die gewone kappie wat die middellae vokale van hul middelhoë teenhangers onderskei het en die omgekeerde kappie wat mediaal-palatale artikulasie by sekere konsonante soos byvoorbeeld tšh moes aandui, aangesien dit nie in hjerdie tale moontlik was om dit deur middel van die digraaf sh te doen nie."

ooreenkomstig die beginsels van die IPA sou slegs foneme voortaan ortograEles voorgestel word en nie ook foneemvariante soos vroeër soms gedoen was nie, en war dialektiese variasies in die uitspraak van klanke voorkom, sou hlerdie variasies ook nie meer soos in die verlede ortografies aangedui word nie.

Die uitwerking van standaardisasie was nêrens duideliker waarneembar as in Noord-Sotho nie war die getal skryftekens drasties gekrimp het van ver bo die 100 tot slegs 45 .

Wat die unifikasie van die onderskeie ortografleë betref, was hierdie doelstelling betreklik gou in die twee Ngunitale bereik. Pogings om die skryfwyse van die drie sothotale eenvormig te mak het egter van die begin weinig sukses gehad, deels ondat die samewerking van die destydse Basoetoland nie verkry kon word nie en deels omdat die drie tswana-ortografieë van destyds eers onderling verenig moes word. Hierdle doel ts egter in 1950 verwesenlik toe daç op inisiatief van die Transvalise onderwysdepartement 
daarin geslaag was om 'n gemeenskaplike ortografie vir Noord-Sotho en Tswana daar te stel." Die samewerking van Basoetoland kon egter nie verkry word om ook Suid-Sotho daarby te betrek nie. Wat presies die rede of redes was vir Basoetoland se weiering om saam te werk, is nie bekend nie aangesien die bronne waarin hierdie besluit gedokumenteer is nie (meer) verkrygbaar is nie. Basoetoland se onwilligheid om mee te werk het egter nie die Suid-Afrikaanse owerhede verhinder om eensydig tot ' $n$ aanpassing oor te gaan nie. Die gevolg hiervan was dat elk van die drie Sothotale in die Republiek vandag veel meer toeganklik vir lesers van die ander twee tale is as wat ooit voorheen die geval was.

Die feit dat skrywers van die Suid-Aftikaanse Bantoetale tussen twee teenstrydige metodes van woordverdeling kon kies het warskynlik gedurende die vroegste skryfgeskiedenis van hierdie tale nie veel saak gemaak nie. Namate hierdie tale al meer en meer geskryf begin raak het, was dit net ' $n$ kwessie van tyd voordat die meriete van hierdie twee benaderings aan ' $n$ ernstige wetenskaplike ondersoek onderwerp sou word. So iets het dan ook gedurende die uroeër twintigerjare plaasgevind toe die Departement van Naturelle Sake in die voormalige suid-Rhodesië 'n Suid-Afrikaner by name van prof. C.M. Doke versoek het om ondersoek in te stel na die moontlike vereniging van die onderskeie shonadialekte in daardie land. Doke het gou tot die besef gekom dat ' $n$ eenvormige skryftekenstelsel alleen nie genoeg sal wees om hierdie doel te verwesenlik nie tensy dit nie ook met 'n eenvormige sisteem van woordverdeling gepaardgaan nie. Doke word gevolglik die eerste persoon wat die probleem van woordverdeling in die Bantoetale op ' $n$ wetenskaplike basis ondersoek. Sy ondersoek warby hy verskeie gantoetale waaronder zulu betrek, bring hom tot enkele baie belangrike gevolgtcekkings rakende die woord in die Bantoetale, namlik:

(a) dat woordverdeling in Bantoe op uitspraak gebaseer moet word,

(b) dat alle woorde in die Bantoetale deur die aanwesigheid van een hoofklem wat gewoonlik op die voorlaaste sillabe val, gekenmetk word, en

dat albei hierdie bevindings die konjunktiewe metode van woordverdeling ondersteun.

Doke se opvatting omtrent woordverdeling was feitlik geheel en al deur die Ngunikomitee onderskrywe en hulle beveel gevolglik aan dat hierdie metode 
as die amptelike skryfwyse van hierdie tale erken moet word. Hierdie adnbeveling word later deur die Sentrale ortografiekomitee bevestig. Die Ngunitale sou hierna nooit weep anders as konjunktief geskryf word nie. Latere pogings on die konjunktiewe skryfwyse ook as die amptelike skryfwyse in die Sothotale anvaar te kry het misluk hoofsaaklik ondat die beleidmakers van mening was dat hierdie metode veel minder geskik vir die fonologiese sisteem van die sothotale is as wat die disjunktiewe metode is. Een van die redes wat hiervoor angevoer was, is byvoorbeeld die feit dat die afwesigheid van semivokale tussen sillabes wat slegs uit in vokaal bestaan, die lees en gevolglik ook die uitspraak van woorde in hierdie tale oneindig sou bemoeilik indien ' $n$ konjunktiewe benadering gevolg sou word. in Sin 500 syvoorbeeld

9a a apee ("hy kook nie dit nie")

sou dan as

gaaapee

geskryt moes word.

Ten spyte daruan dat Doke se woordteorie ernstige tekortkominge gehad het, soos onder meer die feit dat sy ortografiese woord en sy linguistiese woord, dit wil sê die onderskeie woordsoorte wat hy onderskel, nie altyd saamgeval net nie, het die voordele wat dit vir die skryfstelsels van die Ngunjtale ingehou het die wetenskaplike tekortkominge daarvan ver oortref. Na die aanname van die Dokeanse standpunt was die $10 s$ of vas skryf van woorde nog nooit weer 'n kwessie in die Ngunitale nie. Trouens, die uniformiteit en sekecheid wat hierdle benadering onder skryuers van hierdie tale tot gevolg gehad het, het 'n geweldig stimulerende invloed op die groei van hul onderskeie letterkundes gehad.

Die verwerping van Doke se konjunktiewe benadering en by implikasie ook sy woordteorie, het tot gevolg gehad dat die Ngunitale een belangrike ortografiese voordeel bo die ander Bantoeskryftale in hierdie land gehad het, naamlik ' $n$ duidelik gedefinieerde ortografiese woord--- iets wat geheel en al in die ander tale ontbreek het en trouens vandag nog ontbreek.

Hlerdie belangrike tekortkoming in hul skryfsisteme het byvoocbeeld die Sothutale genoodsaak om talcyke reëls in verband met woordverdeling neer te lê, lets wat byvoorbeeld nie in die Ngunitale nodig was nie. So byvoorbeeld het tswana nie minder as 16 reëls por woordverdeling nie terwyl zulu daaronteë mad slegs twee het. Dit is egter nie soseer die aantal reëls oor 
woordverdeling wat die spelling van die sothotale soms so in nagmerrie mak nie mar die feit dat dit nie bekend is wat die motivering agter hierdie reëls is nie. Sodanige motivering sou warskynlik baie gehelp het om die verwarcing en onsekerheid op te klaar wat so dikwels teëgekom word in gevalle war daar uitsonderings op hierdie reëls bestaan en wat dan, oppervlakkig geoordeel, na inkonsekwente spelwyses lyk. Die volgende voorbeelde uit Noord-Sotho illustreer wat hier bedoel word. Die bywoordelike voorvoegsel ga- word normalweg vas geskrywe, maar om die een of ander rede word dit in sekere gevalle weer los geskryf teenoor die bywoordelike voorvoegsel ka wat normalweg weer los geskrywe word, mar om redes wat nie duidelik is nie in ander gevalle weer vas geskrywe word, die enumeratiewe stamme -fe en -pe wat vas geskryf moet word teenoor die ander enumeratiewe stamme wat los geskrywe word, die assosiatiewe na wat soms vas en soms weer los geskryt moet word, ensovoorts.

Die stand van die skryfstelsels van die onderskeie suid-Afrikaanse Bantoeskrytale was min of meer soos in die vorige paragrawe uiteengesit toe die Sentrale Regering in 1954 besluit het om alle Swart onderwysdienste vanaf die Provinsiale Administrasies na die degtydse Departement van Naturelle sake oor te plaas. Hierdie dienste sou voortaan behartig word deur die afdeling Bantoe-onderwys wat in 1958 'n afsonderlike staatsdepartement word. As eerate stap vir die nuwe bedeling word' $n$ oorhoofse Bantoetaalraad in die lewe geroep. Hierdie Raad word die hoogste gesag om besluite rakende die Bantoeskryftale van Suid-Afrika te neem. Terselfdertyd word daar vyf taalkomitees gestig, naamlik die taalkomitee vir sotho,s zulu, Xhosa, venda en Tsonga. Elk van hierdie komitees word saamgestel uit 'n aantal akadenici wat in die meeste gevalle dosente in die betrokke swart tale an Blanke universiteite was.

Met die standaardisering van hul onderskeie ortografieë agter die rug, of minstens gedeeltelik agter die rug, kon hierdie komitees hul aandag ook aan ander sake begin skenk. Een van die knellendstes was die skep van nuwe terme. 
voor die koms yan die witman na hierdie land was die Swartman se tale aangepas aan ' $n$ omgewing warin, onderwys, die Christelike godsdiens, die moderne landbou, die nywerheid en tegniek en hulle produkte, en dergelike ander fasette en voortvloeisels van die Westerse beskawing geen rol gespeel het nie. Soos die Swartman al meer met hierdie dinge te doen gekry het, so het die behoefte by hom al groter geword om ook in sy eie taal na hierdie dinge te kan verwys en daaroor te praat. Hiervoor het hy sekere terme en uitdrukkings nodig gehad wat egter in sy eie taal ontbreek het. Die enigste manier warop hierdie probleem beredder kon word, was vir hom om nuwe terme te skep.

Een van die terreine war hierdie behoefte die eerste en dringendste aangevoel was, was die onderwys war moedertaalonderrig op die primêre skool die skryf en vertaal van teksboeke in die onderskeie swart tale 'n knellende probleem gemakk het vanweë die talle uitheemse terme en begrippe wat noodwendig dascby betrokke was. Om hierdie probleem te help verlig, stel die destydse Departement van Bantoe-onderwys ' $n$ woprdelys saam wat in die eerste plek bedoel was om in die primêre skool gebruik te word en hoofsaaklik uit die sillabusse van die verskillende vakke vir die primêre skool geneem was. By hierdie lys word $\infty$ terme ingesluit wat deur skrywers en vertalers van skoolhandboeke benodig mag word sowel as 'n aantal algemene terme warvoor daar ' $n$ behoefte buite skoolverband bestaan het. As die mees bevoegde en ook enigste amptelike liggaam rakende Bantoetaalsake, word hierdie taak aan die Bantoetaalrad, en by Implikasie, aan die onderskeie taalkomitees opgedra.

War die behoefte aan nuwe terme aanvanklik grootliks tot die onderwys beperk was, het dit gou uitgebrei na ander terreine van die openbare lewe. Instansies wat spoedig ' $n$ geweldige behoefte aan die skep van nuwe terme ontwikkel het, was die verskillende swart radiodienste van die saur. Die tientalle nusbulletins wat elke dag oor dle verskillende swart senders uitgesaai moet word tesame met programme soos sportuitsendings, het in ernstige behoefte an nuwe terme laat ontstaan. Omdat die onderskeie taalkomitees nie alleen in staat was om die hoeveelheld werk wat skieli-k langs hierdie weg na hulle gekom het, te behartig nle, moes die sauk noodgedwonge 'n eie swart tadidiensafdeling in die lewe roep wat spesiaal na hierdie probleem moes omsien. Op hierdie wyse kon die uitsaaiwese ' $n$ onskatbare 
bydrae tot die ontwikkeling van ons swart tale lewer en lewer hulle dit vandag nog steeds.

Hoewel daar geen vaste voorskrifte bestaan warvolgens nuwe terme geskep moet word nie kan daar nogtans ' $n$ par tendense in hierdie verband onderskei word. Hulle is

(a) deur betekenisverbreiding warvolgens die betekenisse van bekende woorde so uitgebrei word dat hulle ook bruikbaar word ten opsigte van verskynsels van die moderne tyd. So byvoorbeeld word in zulu die woord kerf ook vir skrymerk doen gebruik, en die woord doodmaak vir kanselleer ensovoorts;

(b) deur letterlike vertalings. Die zuluwoord vir verkyker byvoorbeeld is 'n letterlike vertaling van hierdie woord in Afrikans.

(c) deur heeltemal nuwe terme te skep. Die amptelike zuluwoord vir verkeersknoop is die dreigende stand van dinge wat op wiele loop;

(d) deur ontlenings uit Engels en AErikaans. Sodanige worde word gewoonlik geherstruktureer om in te pas by die fonologiese en grammatiese wette van die betrokke swart taal. In die proses van herstrukturering raak sulke woorde dikwels onherkenbaar soos byvoorbeeld die Noord-Sothowoord mebotoro wat die meervoud is van die word motoro wat weer afkomstig is van die Afrikanse woord motor.

Toe die eerste selfregerende state gedurende die sewentigerjare onafhanklikheid ontyang het, het dit ook tot ' $n$ heeltemal nuwe bedeling in die beheer van die onderskeie taalkomitees aanleiding gegee. In die eerste plek is die oorhoofse Bantoetaalraad afgeskaf en is die onderskeie taalkomitees onder die jurisdiksie yan die Departemente van Onderwys van die betrokke selfregerende en onafhanklike state geplaas. Hulle sou voortaan outonome liggame wees, oor ' $n$ eie konstitusie beskik en as taalcade bekendstaan. Benewens lede van die betrokke onderwysdepartement waruit die voorsitter en onder-voorsitter gewoonlik gekies word, sou onder andere die volgende liggame ook op die taalrade verteenwoordig word: 
http://spilplus.journals.ac.za/

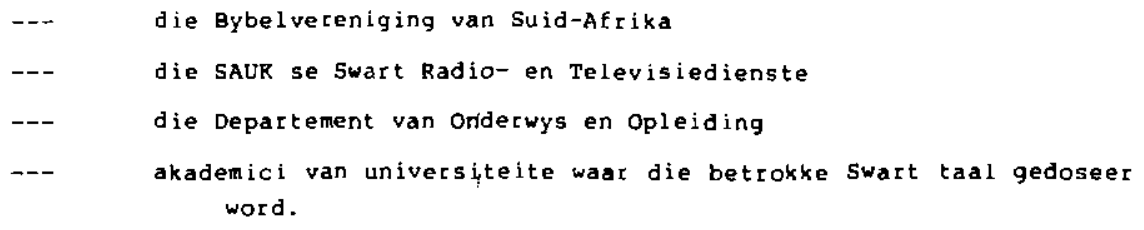

Die taalraad word amptelik as elke swart taal se hoogste gesagsliggaam erken en sy besluite is gevolglik bindend op die betrokke taal in sowel die Swart staat as in die Republiek. In geval van swazi wat in die Republiek sowel as in Swaziland gepraat word, is die taalraad se gesag net tot die Republiek beperx. Daar is egter ' $n$ goeie onderlinge verstandhouding tussen die Swaztaalraad van Suid-Afrika en sy teenhanger in 5waziland, met die gevolg dat daar ' $n$ eenvormige taalbeleid met betrekking tot swazi in beide lande gevolg word. Wat suid-Sotho betref, is die pooisie soos reeds verduidelik is, minder gunstig.

Benewens finale seggenskap oor alle ortografiese en verwante aangeleenthede soos woordverdeling, afkortings, punktuasie, ensovoorts, lewer die taalrade ook finale uitsprake oor terminologie en vaktaal asook oor die spelling van plekname binne die grense van die betrokke swart staat. 
Hierbenewens het die taalrade ook nog die taak om Bantoetaalboeke te keur en te gradeer vir gebruik op alle sekondêre swart skole asook om Bantoetadboeke vir alle departementele eksamens vir voorskryfdoeleindes aan te beveel. Deur die laasgenoemde twee funksies beskik die taalrade oor 'n uiters effektiewe manier om toe te sien dat alle voorskrifte rakende die ortografie en verwante sake soos woordverdeling nagekom word, aangesien boeke wat $n$ ie an hierdie voorskrifte beantwoord nie, of wat nie van die amptelike terminologie gebruikmak nie, sonder meer deur die taalrade afgekeur word en gevolglik nie vir skoolgebruik aanbeveel word nie. Hierdie besluite is bindend en word gewoonlik deur die Departement van Onderwys aanvaar. As in aanmerking geneem word dat die skoolmark by verre weg die grootste mark vir Bantoetaalboeke is, is dit te begrype warom uitgewers gewoonlik uit hul pad gaan on die voorskrifte van die taalrade so stiptelik as moontlik na te kom. Hoewel die enkele Bantoetaalpublikasies wat nie spesifiek op die skoolmark gerig is nie, soos die een of twee koerante en enkele tydskrifte, hul minder deur die voorskrifte van die taalrade gebonde hoef te voel, bestaan die indruk nietemin dat ook hulle hul graag by hierdie voorskrifte wil hou.

Hoewel dit effens prematuur is on op hierdie staldum 'n vooruitskouing te doen oor wat moontlik die rol van die taalrade in die toekoms gaan wees, het daar tog in die afgelope tyd enkele gebeurtenisse plaasgevind wat op in moontlike verandering in die funksies van talrade in die nabye toekoms $k a n$ dui. Die eerste is die instelling van vakkomitees vir die verskillende tale wat na verwagting die taak van boeke voorskryf en keur by die taalrade sal corneem. Die tweede is die instelling deur die talrade van letterkundepryse met die doel on die ontwikkeling van hul onderskeie letterkundes verder te stimuleer. Derdens is daar reeds deur sommige taalrade 'n begin gemaak om die tradisies en gewoontes van hul onderskeie volke te dokumenteer. In die lig van al hierdie gebeure wil dit dus voorkom asof die Bantoetaalrade in die toekoms dalk al hoe meer in $r o l$ kan speel wat soortgelyk is aan die van die Suid-Afrikanse Akademie vir Wetenskap en Kuns, dit wil sê dat hulle hulle al hoe meer op die bevordering van hul onderskeie volke se taal. letterkunde en kultuur gaan toele. En in hierdie verband is dit miskien goed on te onthou dat geeneen van hierdie doelstellings moontlik sou gewees het as dit nie vir die tydige standardisering van die betrokke Bantoetale se skrytstelsels was nie. 
http://spilplus.journals.ac.za/

NOTE

Lestrade: 1928:261-273 (Aang'ehaal uit (Esterhuyse 1974)).

2 Practical Orthography of African Languages: 1927:3.

3 Die kappie sou later net in wetenskaplike publikasies gebruik word.

- Dit het wel beteken dat Noord-sotho vir enkele konsonante alternatiewe skryftekens moes onderskei. Hierdle beslult is egter in 1967 herroep.

5 Die sothotaalkomitee sou later in 3 onafhanklike komitees verdeel, namlik een vir Noord-Sotho, een vir Tswana en een vir Suid-Sotho. 


\section{BIBLIOGRAFIE}

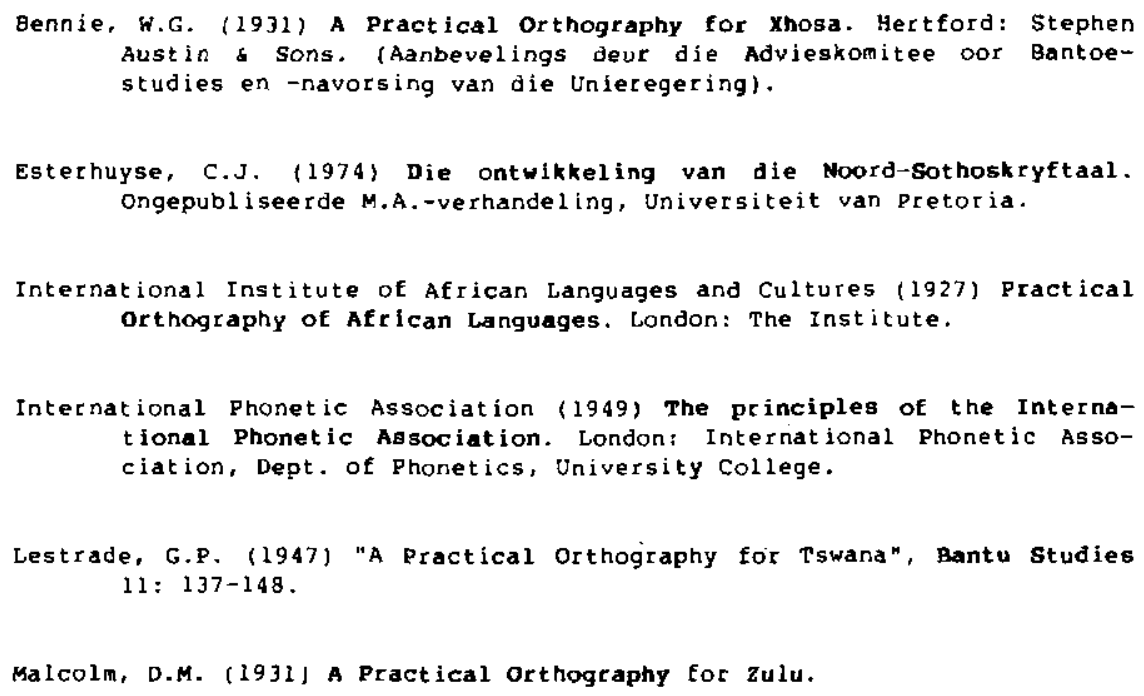

Van Wyk, E.B. (1966) Die Bantoetale: 'n beknopte algetsene oorsig. Pretoria: Van Schaik. 